\title{
Sociodemographic Factors Influencing the Experience of Ethical Dilemmas Among Nurses in Critical Care Unit of Kenyatta National Hospital
}

\author{
Jostine Ndunge Mutinda ${ }^{1}$, Miriam Wagoro ${ }^{2, *}$ \\ ${ }^{1}$ School of Nursing, University of Embu, Embu Town, Kenya \\ ${ }^{2}$ School of Nursing, University of Nairobi, Nairobi City, Kenya
}

Email address:

jostinem2013@gmail.com (J. N. Mutinda), atienomo@yaho.com (M. Wagoro)

*Corresponding author

\section{To cite this article:}

Jostine Ndunge Mutinda, Miriam Wagoro. Sociodemographic Factors Influencing the Experience of Ethical Dilemmas among Nurses in Critical Care Unit of Kenyatta National Hospital. American Journal of Nursing Science. Vol. 6, No. 2, 2017, pp. 113-124. doi: 10.11648/j.ajns.20170602.15

Received: November 22, 2016; Accepted: January 9, 2017; Published: February 24, 2017

\begin{abstract}
Ethical issues have emerged in the recent years as a major component of health care for the critically ill patients, who are vulnerable and totally depend on nurse working in the critical care unit. The perception and magnitude of ethical dilemmas faced by nurses working in critical care unit of Kenyatta National Hospital (KNH) as well as the sociodemographic factors influencing this experience had not been determined. This exploratory survey was conducted on 123 nurses working in three critical care areas of the Kenyatta National Hospital. The research aimed to identify the ethical dilemmas by nurses working in Critical Care Units of the Kenyatta National Hospital in their everyday practice and the socio-demographic factors influencing the experience. Personnel records showed the nurses had varying socio-demographic characteristics which were found to influence the experience of dilemmas. Data were collected using questionnaires which were distributed to the 123 nurses working in the critical care areas. The participants were selected using stratified random sampling method. Data was cleaned and analyzed using SPSS. Chi square test was used to assess the relationship between variables. The following were identified as the emerging ethical issues: end-of-life decisions (prolonging the dying process, withholding treatment, DNR orders and patients' religious values), Patient care issues (unsafe nurse-patient ratios, allocation of scarce medical resources, breaches of patients' privacy, ignoring patients' autonomy, dealing with incompetent colleagues, discriminatory treatment of patients, patient/ relatives uninformed about the patient's prognosis) and human rights issues (advance directives, informed consent, rights of pediatric patients and nursing of critically ill patients posing a risk to nurses). Various factors have been attributed to influencing the way one perceives ethical dilemmas. These include knowledge, age and gender among others. The study focused on the socio-demographic factors that significantly affected the experience of ethical dilemmas which included: age, professional qualification and level of knowledge of ethical issues. In conclusion this study shows that ethical dilemmas are an issue of concern among the nurses working in the critical care units of the KNH. The experience of ethical dilemmas is influenced by various socio-demographic factors.
\end{abstract}

Keywords: Ethical Dilemmas, Critical Care Areas, Critical Care Nursing, Socio-demographic Factors

\section{Background}

Nurses are the largest group of healthcare providers serving in all the facilities providing health services. In Kenya they form $80 \%$ of the workforce as depicted in the Kenya national workforce and training analysis data (16). Nurses are deployed in nearly all the departments in the health care institutions to include the critical care units where they face various issues and are required to make decisions pertaining to patient care.

Contemporary studies done in developed countries have consistently demonstrated that nurses working in critical care units as well as other areas face ethical dilemmas concerning issues of patient management [1]. 
Ethical dilemmas occur when; a problem exists between ethical principles, deciding in favor of one principle usually violates another, or when a situation involves a conflict between two contradictory principles or values. Recently ethical issues have come out as a major constituent of health care for the critically ill patients [14]. This has been due to recent trends in healthcare which have created potential for high levels of ethical dilemmas especially for nurses who are key players in provision of healthcare to the critically ill [8].

These trends include: emigration of nurses creating shortage of nursing workforce, increased public expectation and widespread consumer involvement in healthcare. Other trends include increased numbers of emerging and reemerging diseases, decreased funding for health care, technological and pharmacological advances which are new but expensive [12].

Despite advancement in medical technology many patients spend their final hours in critical care units. Treatment of critically ill patients in today's world is being dictated by latest developments in life sustaining and life saving technology. The greater control over life and death through advanced resuscitative techniques and life support system appears to challenge basic ethical principles. Due to this fact, moral and ethical questions arise concerning: when to stop treatment, who should decide and what criteria should be applied in arriving at the decision [6].

The International Council of Nurses (ICN) Code of Ethics for Nurses has four principal elements that outline the standards of ethical conduct displaying a reflection of the ethical principles governing care in the critical care units. The first one is on the Nurse and people: To enhance the protection of patients' rights to confidentiality and informed consent the patient/ legal proxy should receive sufficient information on which to base consent for care and related treatment. The second one is on the Nurse and practice which advocates for professional accountability on the part of the nurse working in the critical care areas (advocacy). The third one is on the Nurses and profession in which the nurse participates in creating and maintaining safe, equitable social and economic working conditions in the critical care area (justice). Lastly is the Nurse and coworkers which advocates that nurses take appropriate actions to safeguard individuals, families and communities when their health is endangered by a coworker or any other person (non-maleficence) [13].

Studies have revealed that both nurses and physicians face ethical dilemmas pertaining to end-of-life decisions, patient care and social conflicts [7, 11]. Despite the magnitude of ethical dilemmas faced in critical care areas there is little documented information concerning the role played by critical care nurses in resolving them. Moreover studies have shown that nurses and do not follow a systematic pattern of ethical decision making $[5,8]$. In addition there is evidence that socio-demographic factors of the nurses working in the critical care units exert a big influence on the nurses' involvement in ethical decision [5] making.

\subsection{Problem Statement}

Ethical dilemmas are a source of stress for health professionals and remain one of the major concerns in the nursing profession that require urgent attention in Kenya [3]. The dilemmas occur due to changes in health care delivery which has created new nursing roles and responsibilities, raised new questions and produced new stressors. Other sources of ethical dilemmas are the complexity of patient health problems and the increasing use of high technology which can lead to increased patient morbidity and mortality [2]. As the provision of care to the critically ill becomes more composite and the profession of nursing more autonomous, professional accountability cannot be overemphasized. The complex nature of the health problems faced by patients admitted in ICU coupled with extensive use of very sophisticated technology requires at times rapid decision making. These critically ill patients are vulnerable and entirely depend on the caregiver, optimally the nurse working in the critical care unit [1].

The nurses working in the critical care areas also have various socio-demographic factors which may affect how they perceive ethical dilemmas and their ethical decision making process.

Despite the importance of ethical dilemmas faced by these nurses, little is known about their prevalence, causes, effects and factors affecting their resolution. The existing literature focuses primarily on the problem of nursephysician conflict, and nurse-family conflict, and emphasizes coping mechanisms for nurses rather than improving patient care $[11,15]$. Several Studies conducted in other countries e.g. Turkey, Sweden and Australia revealed the evidence of ethical dilemmas experienced by nurses working in critical care units. [7, 8, 11]. However searches have not revealed any results of a study conducted on this area, in a public hospital of a developing nation. Previous studies also revealed that socio-demographic characteristics of the nurses affect how they perceive ethical dilemmas. According to personnel records in the critical care units of KNH (as availed by the Assistant chief nurses in the respective areas of study) the nurses working in these areas have varied qualifications and clinical experiences as well as age differences among other sociodemographic characteristics. However the ethical dilemmas they face while working in these areas, their magnitude, and how they perceive and resolve them have not been studied. Moreover, studies have identified gaps in ethical decision making process among critical care nurses in other countries [4, 10]. These gaps usually occur due to their perception of the ethical problems.

\subsection{Purpose of the Study}

The study sought to identify the dilemmas and the sociodemographic factors affecting their perception. 


\section{Methods}

\subsection{Study Design}

This was an exploratory survey of 120 nurses working in three critical care areas of the $\mathrm{KNH}$. Exploratory surveys are carried out to obtain more information in areas in which little information is available.

\subsection{Variables Under Study}

\subsubsection{Independent Variables}

Common ethical principles and nurses' socio-demographic data i.e. age, sex, level of nursing education, post-basic training, years of experience were considered as the independent variable.

\subsubsection{Dependent Variables}

The dependent variables for this study included the types, frequency and resolution of ethical dilemmas.

\subsection{Study Area}

The study was conducted in the Intensive care, renal and the burns units at the Kenyatta National hospital. KNH is a national referral and teaching hospital in Kenya which receives patients from all over the country. It has a bed capacity of twenty one in the intensive care unit which makes it the largest ICU in the country. The burns unit has a bed capacity of eighteen while the renal unit has twelve dialysis machines. An average of thirty six patients is dialyzed per day. Critically ill patients are admitted in these three units of the KNH. Being a public national referral hospital it caters for patients of different social classes, ages and illnesses. Due to the large number of patients admitted there, $\mathrm{KNH}$ faces problems of scarcity of resources which may put the nurses in a dilemma as to how to prioritize the allocation. Problems may arise with confidentiality because of the hospital set up (no partitions) coupled with the fact that it is a teaching hospital whereby a patient's diagnosis may be known by the others during hospital rounds. Some patients may not afford the expensive treatment (for instance when required to buy some drugs) in the critical care unit and these put the nurses in a dilemma of withholding treatment. There are many critically ill patients who are brought in by the police following road accidents and whose relatives may not be traced hence decisions concerning their management are done without their consent or that of their relatives which violates the principle of informed consent.

This mix of clients implied that different ethical issues were bound to be encountered during the provision of care to these patients. These coupled with the fact that $\mathrm{KNH}$ is located in an urban area where the clients who mostly seek for services there are informed made $\mathrm{KNH}$ an ideal facility for the purpose of this study. Based on what previous studies had shown (literature review) about the dilemmas experienced by nurses and the fact that $\mathrm{KNH}$ being a National Teaching and research hospital should have the most experienced and qualified nurses. This coupled with their work experience and decision making process made the facility to be considered ideal for this study. It was hence purposively sampled as the study area.

\subsection{Study Population}

This constituted a total of all (184) nurses working in the critical care areas in $\mathrm{KNH}$ since they were all eligible for the study save for the exclusion criteria.

\subsection{Sample Size Determination}

The sample size was determined using the Fisher et al 1999 formula for determination of sample size [3].

$$
\mathrm{n}=\frac{\mathrm{z}^{2} \mathrm{pq}}{\mathrm{d}^{2}}
$$

where $\mathrm{n}=$ desired sample size (if the target population is over $10,000)$

$\mathrm{z}=$ the standard normal deviate at $95 \%$ confidence interval $(=1.96)$.

$\mathrm{p}=$ the proportion in the target population estimated to have faced and handled ethical dilemmas in critical care nurses. The estimated proportion of those who have experienced the problems is not known.

$q=1-p, d=$ level of precision (set at + or $-5 \%$ or 0.05 ).

Substituting the above formula with figures:

$$
\mathrm{n}=\frac{(1.96 \times 1.96) \times(0.5 \times 0.5)}{0.5 \times 0.5}=384.16
$$

Since the target population is less than 10,000 the sample size shall be determined using the following formula:

$$
\mathrm{Nf}=\frac{\mathrm{n}}{1+(\mathrm{n} / \mathrm{N})}
$$

Where $\mathrm{Nf}$ is the desired sample size when the target population is less than 10,000 .

$\mathrm{n}=$ the desired sample size when the target population is less than 10,000 .

$\mathrm{N}$ is the estimate of the population size which as per the above calculation is 384 .

$$
\begin{gathered}
\text { Hence } \mathrm{Nf}=\frac{384}{1+(384 / 184)} \\
=123 \text { nurses. }
\end{gathered}
$$

Out of these 3 did not return their questionnaires hence the study sample had 120 respondents.

\subsection{Sampling Frame and Procedure}

The area of study (critical care areas in $\mathrm{KNH}$ ) was be identified using non-probability (purposive) sampling method as the hospital has the largest critical care unit in the country admitting patients from all walks of life. Purposive sampling was chosen because it enabled the researcher to choose a sample from a population that is likely to generate the information required for the study in relation to the objectives. It was assumed that nurses 
working in the critical care areas were more likely to face ethical dilemmas related to critical care than those working in other areas.

Stratified random sampling was used at the unit level in relation to the proportion of nurses working in each unit. To ascertain the number of subjects required from each unit for proportionate allocation, the following formula was used;

$$
\left[\frac{\mathrm{n} 1}{\mathrm{~N} 2}\right] \mathrm{nf}
$$

Whereby: $\mathrm{n} 1=$ number of nurses in a specific unit, $\mathrm{N} 2=$ total number of nurses in the three critical care areas and $\mathrm{nf}=$ minimum sample size.

Simple random sampling method was then applied to come up with the desired sample size in each unit.

As per the records of the duty rosters availed by the assistant chief nurses in the critical care areas, the nurses have been distributed as follows; 110 in the ICU, 44 in the renal unit and 30 in the burns unit adding up to 184 nurses. Out of these, a hundred and twenty three were sampled to participate in the study. The sample frame was as follows:

Table 1. Sample frame.

\begin{tabular}{ll}
\hline Critical care unit & Number of participants \\
\hline Critical care unit & 74 \\
Burns unit & 21 \\
Renal unit & 28 \\
\hline
\end{tabular}

NB: Inclusion and exclusion criteria were considered when sampling the respondents.

\subsection{Data Collection}

\subsubsection{Research Instruments}

A 40 items self administered Questionnaire was prepared by the researcher and distributed to the participants. The questionnaire is a modification of Fry and Duffy Ethical issues scale [9]. which was used for psychometric analysis of ethical issues in 2002. It had five parts: part one had questions on socio-demographic information of the participants. The other parts had questions on the nurses' knowledge of ethical issues, dilemmas on: end-of-life issues, patient care and human rights; and how to handle the dilemmas. The questionnaire was developed based on extensive review of literature related to common ethical problems that face nurses and was modified to suit the research. It contained questions framed to guide the participants in giving the required information. The questionnaire was used to collect demographic data of the participants as well as information pertaining to ethical dilemmas they experience and how they resolve them. It was modified to exclude issues of personally disturbing ethical dilemmas and the most preferred topics while addressing education needs among others.

\subsubsection{Validity and Reliability}

The validity and reliability of the questionnaire was ensured through pre-testing of the questionnaire. Validity of an instrument is a determination of how well the instrument reflects the abstract concept being examined while reliability is concerned with the consistency of the measurement technique [13]. The questionnaire was pretested in the accident and emergency unit of the KNH whereby 5 nurses were randomly sampled for pretesting. Each of the nurses participating during pre-testing was given a questionnaire to fill in. The information obtained from the pre-test was analyzed and used to aid in making amendments to the questionnaire.

\subsubsection{Data Collection Methods}

Permission to conduct the research was sought from the University of Nairobi and $\mathrm{KNH}$ ethical research committee. Further permission was sought from the Assistant chief nurses in the renal, critical care and burns units. Data was collected using self administered questionnaires which were distributed by the research assistants and the researcher. Those sampled to participate in the study were requested to read and sign the consent for the study then fill in the hand delivered self administered questionnaire with the information requested. The questionnaires were then collected by the research assistants for data analysis by the researcher. Use of self administered questionnaires saved time as the information was collected simultaneously.

\subsection{Data Management}

\subsubsection{Data Cleaning and Entry}

Data from complete questionnaires were coded and entered into the computer for analysis.

\subsubsection{Data Analysis and Presentation}

Data analysis was undertaken using the SPSS (statistical package for social studies). Descriptive statistical analyses were performed on the data relating to questions based on three major areas. The aim of these analyses was to summarize the nurses' responses on a number of issues within these major areas. These were: ethical dilemmas experienced by the respondents and the magnitude, actions taken to resolve the dilemma and the factors influencing the experience of dilemmas. The main quantitative statistics were based on frequencies, percentages and means of variables. The relationship between variables were determined and expressed by use of chi square method of data analysis. $\mathrm{P}$ value was set at 0.05 .

Data presentation was done using pie charts and frequency distribution tables.

\subsection{Ethical Considerations}

\subsubsection{Study Approval}

Approval to conduct the research was sought from the Kenyatta National Hospital/ University of Nairobi ethics and research committee and the $\mathrm{KNH}$ administration. Permission 
to access the participants was sought from the unit assistant chief nursing officers in-charge of the three critical care units.

\subsubsection{Study Duration}

The study took six weeks from the day of commencement of data collection.

\subsubsection{Informed Consent}

There was full disclosure of information whereby participants were given an explanation of what they needed to know about the study which included the purpose and benefits of the study. They were also told what was required of them to ensure that they understand the components of the questionnaires and the information they were required to give. Verification to this understanding was done to ensure that the participants were competent enough to give the required information. Participants were then required to sign a consent form once they accepted to participate. Participation was voluntary without any coercion and participants were free to withdraw at any point.

\subsubsection{Confidentiality}

The participation was based on trust, confidentiality guaranteed and the participants were not required to write their names on the questionnaires. Data was coded and during processing and publishing the names will not be indicated in the report.

\subsubsection{Declaration of Interest}

The investigator declares that there was no conflict of interest between self and the stake holders (training institutions, research hospital).

\section{Results}

This chapter reports the findings of this study based on quantitative data gathered from 120 respondents. Out of the 123 questionnaires distributed 3 of them were not returned. After data cleaning one questionnaire was found to have missing information on the gender of the respondent hence it was not analyzed in regard to this variable. Eight respondents did not indicate their age hence these questionnaires were not considered when analyzing this variable.

\subsection{Demographic Characteristics of the Respondents}

\subsubsection{Gender}

All the 120 respondents reported their gender except one. Figure 1 shows that out of those who reported $(n=119) 58$ percent were female while $42 \%$ were male. This gender distribution may be explained by the evolution of nursing as a female dominated profession.

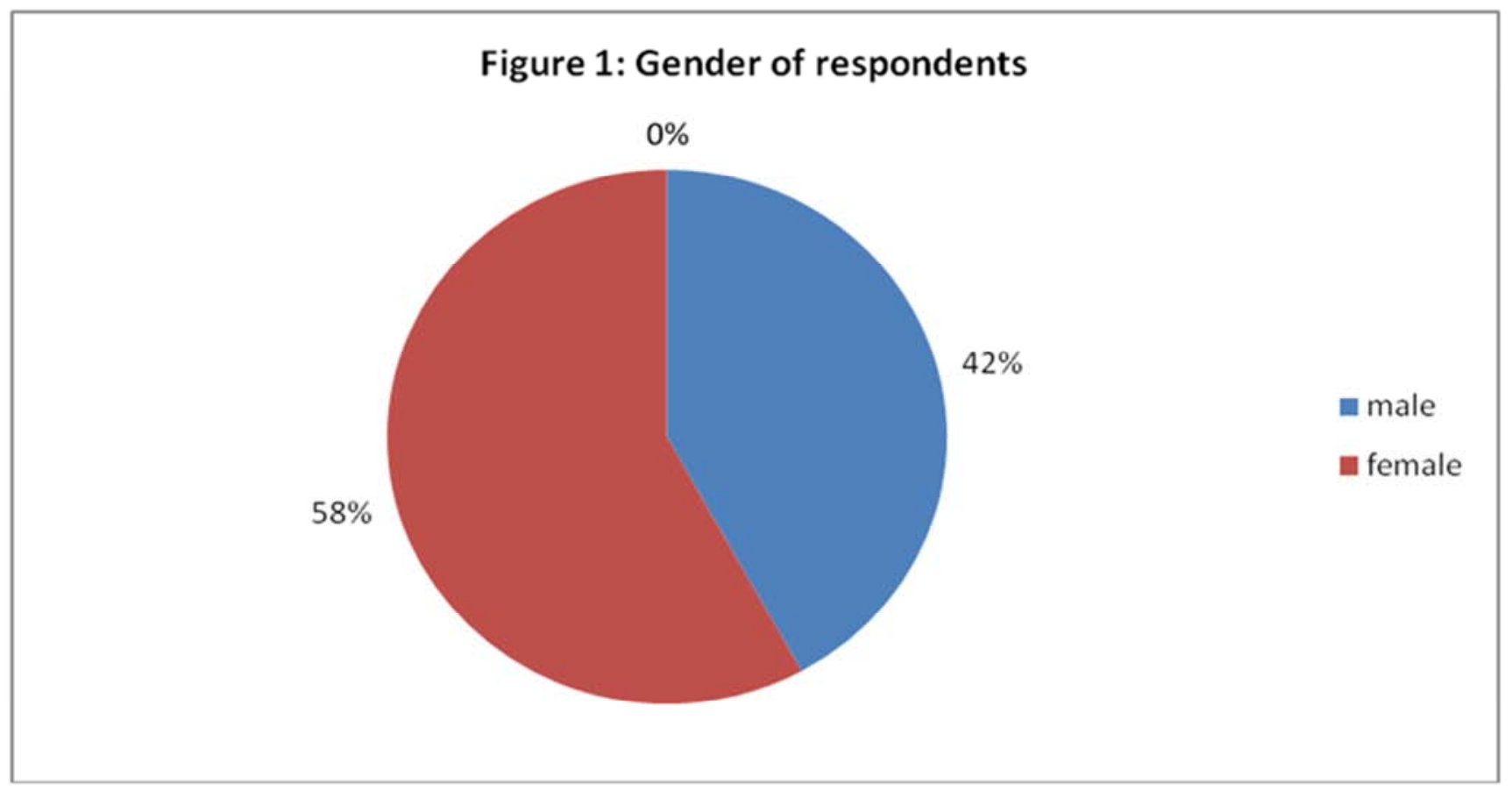

Figure 1. Distribution of the gender of the respondents.

\subsubsection{Age}

Out of the 120 respondents, 8 did not indicate their age. Of the 112 respondents who indicated age, most were in age group 35-39 yrs (36.6\%) followed by 30-34 years at $27.7 \%$. Minimum and maximum ages of the respondents were 25 and 48 years respectively, giving a range of 23 years. The median and modal age was the same, 36 years. The table bar chart (figure 2) below shows age frequency distribution of the ages of respondents in each age group. The distribution shows that a big percentage $(71.3 \%)$ of the nurses working in the critical care units is aged below 40 years of age. 


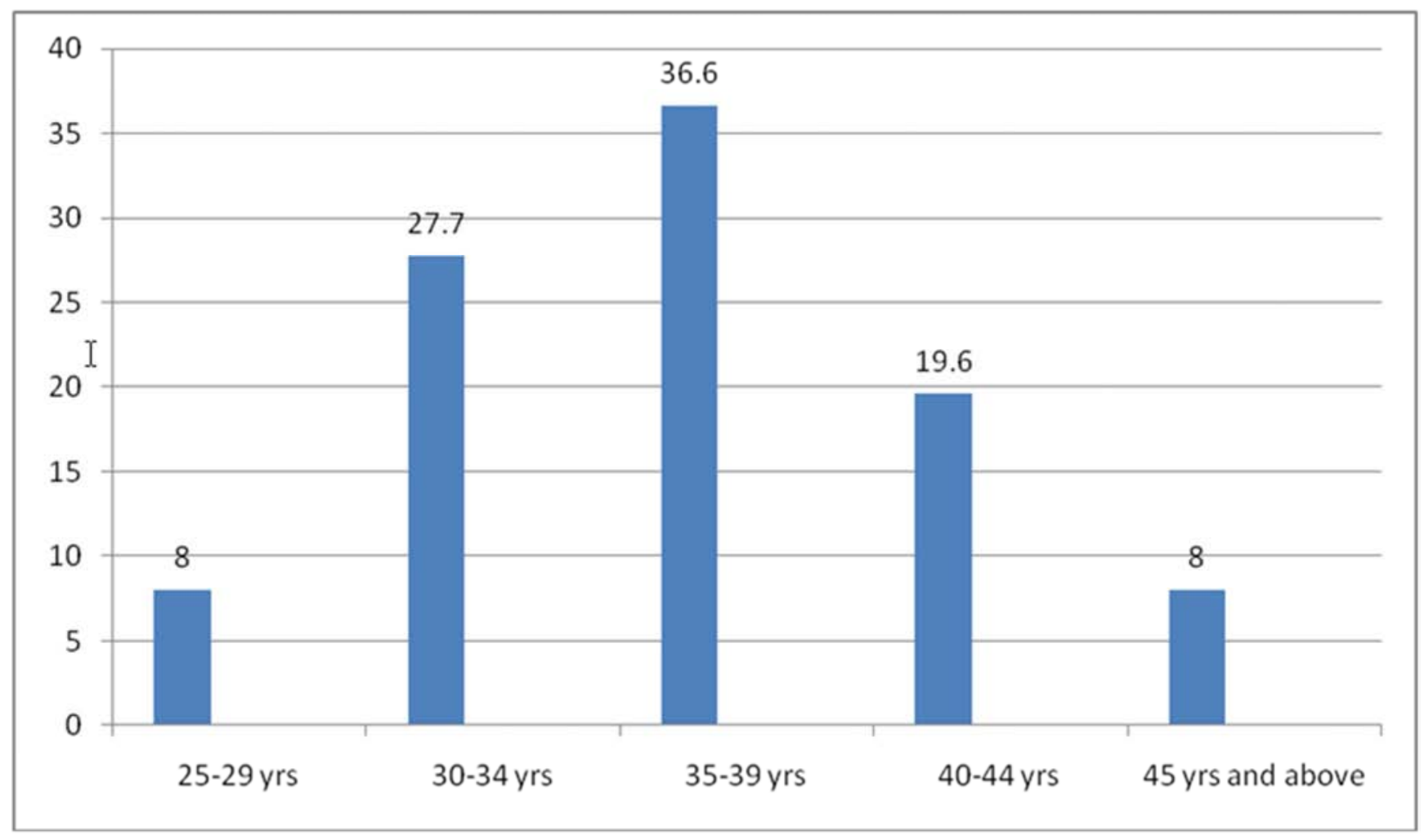

Figure 2. Age distribution (in years) of the respondents. $N=112$.

\subsubsection{Professional Qualification}

As seen from table 2, over two thirds of respondents, $67.5 \%(81)$ had a post basic diploma as the highest level of education, followed by diploma holders at $23.3 \%(28) .7 .5 \%$ (9) had a basic degree in nursing while $1.7 \%$ (2) who formed the least number had a master's degree. This distribution represents the trends in nursing education in Kenya where most of the nurses are trained at diploma level, a few have degrees and very few are training in masters and remaining as clinical nurse practitioners. This study sought to establish if there was a significant relationship between the experience of ethical dilemmas and the professional qualification of the nurse among other factors. To determine whether the above observation was significant, the cross tabulations were subjected to Chisquare test. The results showed a Chi-square statistic of 6.455 with a $p$-value $=0.011$, which means that there was a significant relationship between the two.

Table 2. Respondents' professional qualification.

\begin{tabular}{llll}
\hline $\begin{array}{l}\text { Professional } \\
\text { Qualification }\end{array}$ & Frequency & Percentage & $\begin{array}{l}\text { Cumulative } \\
\text { Percentage }\end{array}$ \\
\hline Masters & 2 & 1.7 & 1.7 \\
Basic degree & 9 & 7.5 & 9.2 \\
Post basic diploma & 81 & 67.5 & 76.7 \\
Diploma & 28 & 23.3 & 100.0 \\
Total & 120 & 100.0 & \\
\hline
\end{tabular}

\subsubsection{Length of Working Experience of the Respondents in the Critical Care Units}

All (120) interviewees responded to this question. Almost a half, 45.8\% (55) had work experience of less than 5 years in the critical care unit, followed by $30.8 \%$ (37) who had working experience of between 6-10 years. This may be explained by the fact that majority of the nurses working in the critical care units are aged below 40 hence majority $(76.2 \%)$ have work experience ranging between 0 and 10 years. The full details are as displayed in table 3 .

Table 3. Respondents' length of work experience in the Critical Care Unit $(C C U)$.

\begin{tabular}{lll}
\hline Length of work experience & Frequency & Percentage \\
\hline Less than 5 yrs & 55 & 45.8 \\
6 -10 yrs & 37 & 30.8 \\
$11-15$ yrs & 26 & 21.7 \\
Over 15 yrs & 2 & 1.7 \\
Total & 120 & 100.0 \\
\hline
\end{tabular}

\subsubsection{Knowledge of Human Rights Issues}

Table 4 shows that majority, $98.3 \%$ (118) of the respondents reported to have knowledge of human rights issues in nursing. However, $1.7 \%$ (2) of the respondents admitted that they were not knowledgeable at all on human rights issues. 
Table 4. Respondents' knowledge of human rights issues.

\begin{tabular}{lll}
\hline Level of knowledge & Frequency & Percentage \\
\hline Not knowledgeable at all & 2 & 1.7 \\
Knowledgeable & 118 & 98.3 \\
Total & 120 & 100.0 \\
\hline
\end{tabular}

\subsubsection{Need for Ethics and Human Rights Education}

Out of the 120 respondents, $56.7 \%$ and $40.8 \%$ expressed the view that there is very great need and a great need for ethics and human rights education. The rest, who comprised a combined minority of $2.5 \%$ either, said there was no need or there was just a slight need for ethics education. This is shown in table 5.

Table 5. Respondents' need for human rights education.

\begin{tabular}{lll}
\hline Extent of need & Frequency & Percent \\
\hline No need & 1 & 0.8 \\
Little need & 2 & 1.7 \\
Great need & 49 & 40.8 \\
Very great need & 68 & 56.7 \\
Total & 120 & 100.0 \\
\hline
\end{tabular}

\subsubsection{Ethics Content Taught}

i. Type of ethics content covered during educational preparation

Table 6 shows that $89.2 \%$ (107) of the nurses surveyed reported having ethics content integrated into regular nursing courses within their curricula. Out of these $12.5 \%, 9.2 \%$, $65 \%$ and $2.5 \%$ reported to have had ethics content: integrated throughout the program of study, taught in a specific course, taught by nursing faculty and taught by non-nursing faculty respectively. $10.8 \%$ reported to have had no ethics content taught during their regular training.

Table 6. Respondents' ethics content taught during educational preparation.

\begin{tabular}{lll}
\hline Type of ethics content & Frequency & Percentage \\
\hline $\begin{array}{l}\text { Content integrated throughout the } \\
\text { program of study }\end{array}$ & 15 & 12.5 \\
Content taught in a specific course & 11 & 9.2 \\
Content taught by nursing faculty & 78 & 65.0 \\
Content taught by non-nursing faculty & 3 & 2.5 \\
No ethics content in coursework & 13 & 10.8 \\
Total & 120 & 100.0 \\
\hline
\end{tabular}

ii. Type of ethics content covered in Continuous Professional Development (CPD)

Table 7 shows the distribution of frequencies of responses concerning the ethical content taught in CPD. 79.2\% (95) of the nurses surveyed reported having ethics content taught in continuous professional development courses. Out of these $24.2 \%(29), 5 \%(6), 43.3 \%(52)$ and $6.7 \%$ (8) reported to have had ethics content: integrated throughout the program of study, taught in a specific course, taught by nursing faculty and taught by non-nursing faculty respectively. $20.8 \%$ (25) reported to have had no ethics content in CPD programs.
Table 7. Respondents' ethics content taught in CPD.

\begin{tabular}{lll}
\hline Type of ethics content & Frequency & Percent \\
\hline content integrated throughout CPD & 29 & 24.2 \\
ethics content specific CPD program & 6 & 5.0 \\
content taught by nursing faculty & 52 & 43.3 \\
content taught by non-nursing faculty & 8 & 6.7 \\
no ethics content in CPD programs & 25 & 20.8 \\
Total & 120 & 100.0 \\
\hline
\end{tabular}

\subsubsection{Availability of Resources for Ethics and Human Rights at Place of Work}

Table 8 shows Distribution on availability of resources to help in ethics and human rights issues. Majority $78.3 \%$ (94) of the respondents reported to have inadequate to totally inadequate resources to help them deal with ethics and human rights issues. Only $21.7 \%$ (26) reported to have adequate resources.

Table 8. Availability of work place resources for ethics and human rights.

\begin{tabular}{lll}
\hline Level of resource adequacy & Frequency & Percent \\
\hline Totally inadequate resources & 42 & 35.0 \\
Inadequate & 52 & 43.3 \\
Adequate & 26 & 21.7 \\
Very adequate & 0 & 0 \\
Total & 120 & 100.0 \\
\hline
\end{tabular}

\subsubsection{Nurses' Experience of Ethical Dilemmas in CCU}

Reference to the pie chart (figure 3) below shows that 97 $(80.8 \%)$ respondents have experienced ethical dilemmas while working in critical care setting.

This finding was in line with the expectations of the researcher as previous studies conducted in other countries revealed that ethical dilemmas were an issue of concern to nurses and other health care professionals.

\subsection{Experience of Ethical Dilemmas Relating to End-of-Life Issues}

As depicted in table 9 below, the commonly experienced ethical dilemma is the one relating to resuscitation orders whereby 76 respondents had experienced it. Out the 76 , majority of them, $62 \%$ (47) had experienced it between 1-5 times for the last one year, while working in the CCU.

This was followed by the experience of dilemmas relating to withholding/withdrawing treatment whereby 58 nurses had experienced it with $53 \%$ (31) of them experiencing it $1-5$ times. 56 respondents reported to have experienced dilemma with matters of prolonging the dying process with $43 \%$ (24) of them experiencing it over 10 times in the last one year.

Issues related to patient's religious beliefs, for instance those opposed to blood transfusion and/or resuscitation procedures posed dilemma to 51 respondents with $55 \%$ (28) of them reporting to have experienced this dilemma 1-5 times in the last one year. 
Table 9. Respondents' experience of various forms of ethical dilemmas relating to end-of-life issues.

\begin{tabular}{|c|c|c|c|}
\hline Type of ethical dilemma & Category of no. of experiences of each dilemma & Frequency of responses & Percentage \\
\hline \multirow{3}{*}{ Prolonging dying process $(n=56)$} & $1-5$ times & 23 & 41 \\
\hline & 6-10 times & 9 & 16 \\
\hline & Over 10 times & 24 & 43 \\
\hline \multirow{3}{*}{ Withholding treatment $(\mathrm{n}=58)$} & $1-5$ times & 31 & 53 \\
\hline & 6-10 times & 15 & 26 \\
\hline & Over 10 times & 12 & 21 \\
\hline \multirow{3}{*}{ Resuscitation (DNR) orders $(n=76)$} & $1-5$ times & 47 & 62 \\
\hline & 6-10 times & 8 & 10 \\
\hline & Over 10 times & 21 & 28 \\
\hline \multirow{3}{*}{ Patient's religious values $(\mathrm{n}=51)$} & $1-5$ times & 28 & 55 \\
\hline & 6-10 times & 11 & 22 \\
\hline & Over 10 times & 12 & 23 \\
\hline
\end{tabular}

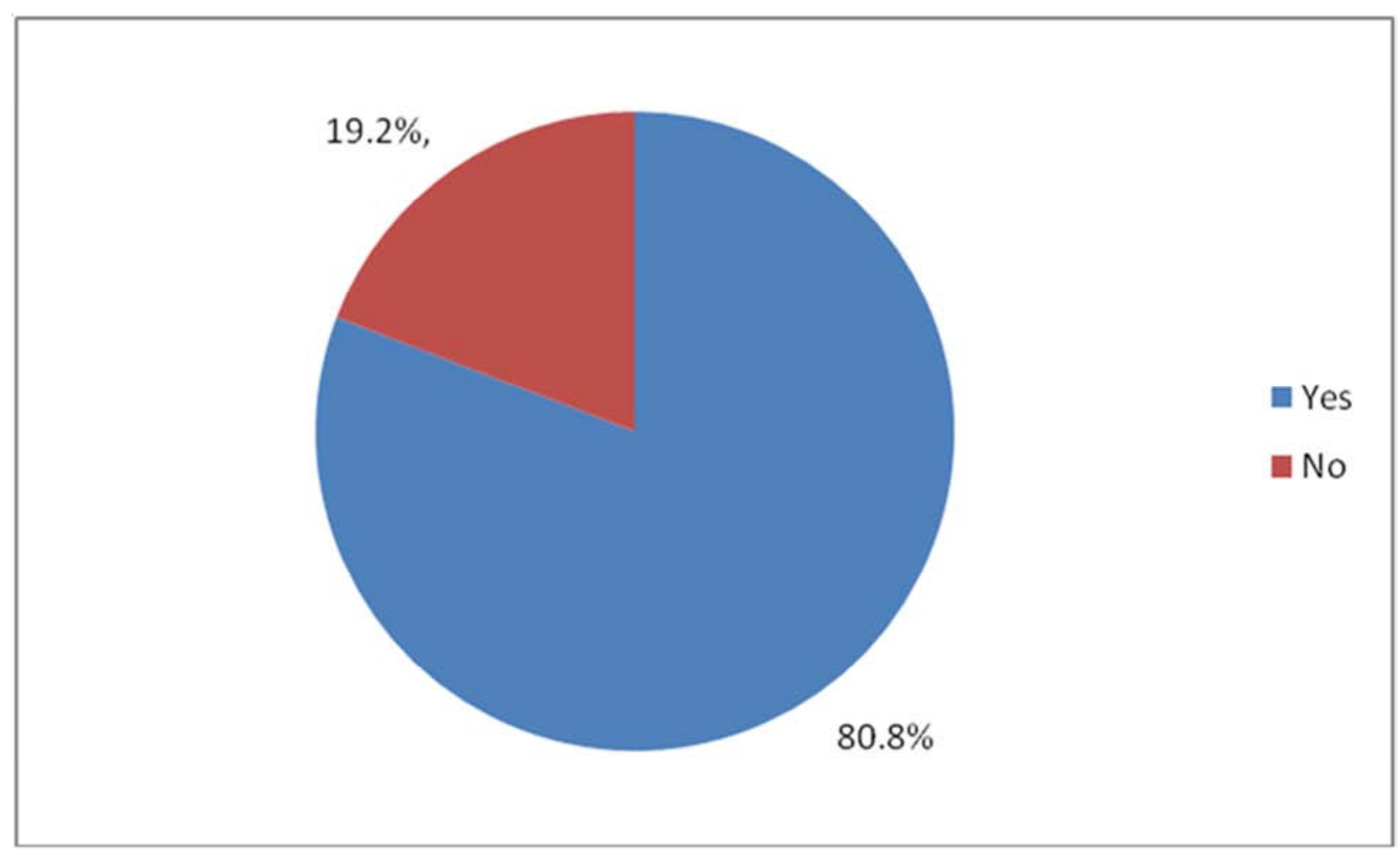

Figure 3. Distribution of frequency on experience of ethical dilemmas.

\subsubsection{Experience of Conflicts over Patient Care Issues}

Table 10 shows the Frequency of experiencing various forms of ethical dilemmas relating to patient care issues (unsafe nurse-patient ratios, allocation of scarce medical resources, breach of patient's confidentiality, ignoring patient's autonomy, dealing with impaired colleague, discriminatory treatment of patients and patients/relatives uninformed about the prognosis of the patient).

As depicted in the table, the most commonly experienced ethical dilemma was the one relating to allocation of scarce medical resources whereby 87 respondents had experienced it. Out of the 87 , majority of them $42.5 \%$ (37) had experienced it between 1-5 times, while $34.5 \%$ (30) had experienced it over 10 times for the last one year, during their working in the CCU. The next commonly experienced ethical dilemma was the one relating to unsafe nurse-patient ratios whereby 80 respondents had experienced it with $48.8 \%$ (39) having encountered it over ten times in the last one year. 40 respondents had experienced breaches of patient privacy with $55 \%$ (22) of them encountering it 1-5 times for the last one year. 28 respondents encountered conflict with ignoring patients' autonomy with $67.9 \%$ (19) of them experiencing that 1-5 times for the last one year. Dealing with patients/ relatives uninformed about the patient's prognosis posed dilemma to 57 nurses with $56.1 \%$ (32) of the respondents experiencing it 1-5 times for the last one year. The other source of dilemma relating to patient care issues was dealing with incompetent/impaired/unethical colleagues whereby 24 respondents reported to have encountered it with $62.5(15)$ of them experiencing it 1-5 times for the last one year. The least source of dilemma was discriminatory treatment of patients which was experienced by only 18 respondents with 11 (961.1\%) experiencing it 1-5 times. 
Table 10. Frequency of experiencing various forms of ethical dilemmas relating to patient care issues.

\begin{tabular}{|c|c|c|c|}
\hline Type of dilemma & Category of No. of experiences of each dilemma. & Frequency of responses & Percentage \\
\hline \multirow{3}{*}{ Unsafe nurse-patient ratios $(\mathrm{n}=80)$. } & $1-5$ times & 26 & 32.5 \\
\hline & 6-10 times & 15 & 18.8 \\
\hline & Over 10 times & 39 & 48.8 \\
\hline \multirow{3}{*}{ Allocation of scarce medical resources $(n=87)$} & $1-5$ times & 37 & 42.5 \\
\hline & 6-10 times & 20 & 23.0 \\
\hline & Over 10 times & 30 & 34.5 \\
\hline \multirow{3}{*}{ Breaches to patient privacy/confidentiality $(n=40)$. } & $1-5$ times & 22 & 55.0 \\
\hline & 6-10 times & 7 & 17.5 \\
\hline & Over 10 times & 11 & 27.5 \\
\hline \multirow{3}{*}{ Ignoring patient autonomy ( $\mathrm{n}=28)$. } & $1-5$ times & 19 & 67.9 \\
\hline & 6-10 times & 5 & 17.9 \\
\hline & Over 10 times & 4 & 14.3 \\
\hline \multirow{3}{*}{ Incompetent/impaired colleague. $(n=24)$. } & $1-5$ times & 15 & 62.5 \\
\hline & 6-10 times & 7 & 29.2 \\
\hline & Over 10 times & 2 & 8.3 \\
\hline \multirow{3}{*}{ Discriminatory treatment of patients $(\mathrm{n}=18)$} & $1-5$ times & 11 & 61.1 \\
\hline & 6-10 times & 1 & 5.6 \\
\hline & Over 10 times & 6 & 33.3 \\
\hline \multirow{3}{*}{ Patient/relatives uninformed about the prognosis. $(\mathrm{n}=57)$} & $1-5$ times & 32 & 56.1 \\
\hline & 6-10 times & 13 & 22.8 \\
\hline & Over 10 times & 12 & 21.1 \\
\hline
\end{tabular}

\subsubsection{Dilemmas Experienced Over Human Rights Issues}

As depicted in table 11, all the respondents (120) attested to the fact that human/patient rights issues were a source of conflict in the critical care units. The most commonly experienced ethical dilemma was the one relating to the fact that nursing the critically ill patients can be risky to the nurse whereby $59.2 \%(67)$ of the respondents agreed with the statement. Violation of rights of pediatric patients was the second most commonly experienced dilemma with $51.7 \%$ (62) of the nurses attesting to the fact that it is a source of dilemma. $46 \quad(38.4 \%)$ respondents reported having experienced conflicts with advance directives while $18.4 \%$ (22) agreed that informed consent was a source of dilemma in the critical care.

Table 11. Human rights issues as a source of dilemma $(N=120)$.

\begin{tabular}{llll}
\hline Type of conflict & Extent of agreement with the statement & Frequency of responses & Percentage \\
\hline & Strongly disagree & 46 & 38.3 \\
Advance directives a source of conflict. & Disagree & 28 & 23.3 \\
& Agree & 35 & 29.2 \\
& Strongly agree & 11 & 9.2 \\
& Strongly disagree & 68 & 56.7 \\
Informed consent can bring conflicts in critical care & Disagree & 30 & 25.0 \\
& Agree & 8 & 6.7 \\
& Strongly agree & 14 & 11.7 \\
Rights of pediatric patients are violated & Strongly disagree & 24 & 20.0 \\
& Disagree & 34 & 28.3 \\
& Agree & 44 & 36.7 \\
& Strongly agree & 18 & 15.0 \\
& Strongly disagree & 21 & 17.5 \\
Nursing critically ill patients can be risky. & Disagree & 28 & 23.3 \\
& Agree & 44 & 36.7 \\
& Strongly agree & 27 & 2.5 \\
\hline
\end{tabular}

\subsection{Magnitude of Various Ethical Dilemmas Experienced by Nurses Working in the Critical Care Units}

For the purpose of this study these dilemmas were grouped into three broad categories which were: Those relating to end-of-life issues, patient care issues and human rights issues.

\subsubsection{Dilemmas Relating to End-of-Life Issues}

As depicted in table 10, the most commonly experienced ethical dilemma is the one relating to resuscitation orders whereby 76 respondents had experienced it. Out the 76 , majority of them (62\%) had experienced it between 1-5 times for the last one year, during their working in the CCU.

This was followed by the experience of dilemmas relating to withholding/withdrawing treatment whereby 58 nurses had experienced it with $53 \%$ (31) of them experiencing it $1-5$ times. 56 respondents reported to have experienced dilemma with matters of prolonging the dying process with $43 \%$ (24) of them experiencing it over 10 times in the last one year.

Issues related to patient's religious beliefs, for instance those opposed to blood transfusion and/or resuscitation 
procedures posed dilemma to 51 respondents with 55\% (28) of them reporting to have experienced this dilemma 1-5 times in the last one year.

\subsubsection{Dilemmas Related to Patient Care Issues}

As depicted in table 11, the most commonly experienced ethical dilemma was the one relating to allocation of scarce medical resources whereby 87 respondents had experienced it. Out the 87 , majority of them $42.5 \%$ (37) had experienced it between 1-5 times, while $34.5 \%$ (30) had experienced it over 10 times for the last one year, during their working in the CCU. The next commonly experienced ethical dilemma was the one relating to unsafe nurse-patient ratios whereby 80 respondents had experienced it with $48.8 \%$ (39) having encountered it over ten times in the last one year. 40 respondents had experienced breaches of patient privacy with $55 \%$ (22) of them encountering it 1-5 times for the last one year. 28 respondents encountered conflict with ignoring patients' autonomy with $67.9 \%$ (19) of them experiencing that 1-5 times for the last one year. Dealing with patients/ relatives uninformed about the patient's prognosis posed dilemma to 57 nurses with $56.1 \%$ (32) of the respondents experiencing it 1-5 times for the last one year. The other source of dilemma relating to patient care issues was dealing incompetent colleagues whereby 24 respondents reported to have encountered it with 62.5 (15) of them experiencing it 15 times for the last one year. The least source of dilemma was discriminatory treatment of patients which was experienced by only 18 respondents with 11 (961.1\%) experiencing it 1-5 times.

\subsubsection{Dilemmas Related to Patient/Human Rights Issues}

As depicted in table 11, all the respondents (120) attested to the fact that human/patient rights issues were a source of conflict in the critical care units. The most commonly experienced ethical dilemma was the one relating to the fact that nursing the critically ill patients can be risky to the nurse whereby $59.2 \%(67)$ of the respondents agreed with the statement. Violation of rights of pediatric patients was the second most commonly experienced dilemma with $51.7 \%$ (62) of the nurses attesting to the fact that it is a source of dilemma. $46 \quad(38.4 \%)$ respondents reported having experienced conflicts with advance directives while $18.4 \%$ (22) agreed that informed consent was a source of dilemma in the critical care.

\subsection{Factors Influencing the Nurses' Experience of Ethical Dilemmas}

Knowledge of ethical issues was considered to have a potential of introducing bias to the study (limitations) hence it was assessed first. To establish this, the respondents' knowledge on human rights issues was assessed as well as the type of ethics content taught to nurses both in regular and CPD programs. The socio-demographic characteristics of the respondents assessed for the purpose of this study were: age, gender, professional qualification and work experience. To determine whether there was any significant relationship between the experience of ethical dilemmas and the various socio-demographic characteristics, Chi square test was utilized. The $\mathrm{p}$ value was set at 0.05 and the results were as follows.

\subsubsection{Knowledge of Human Rights Issues}

Although 98.3\% (118) of respondents (nurses) reported they were knowledgeable about ethics/human rights issues in nursing practice, $97.5 \%$ (97) of them believed they had a great/ very great need for more education on ethical issues. Only $2.5 \%$ (3) felt only a 'slight or no need' for such education.

\subsubsection{Gender Versus Ethical Dilemma}

58 percent of the respondents were female while $42 \%$ were male. This gender distribution may be explained by the evolution of nursing as a female dominated profession. To determine whether there was a significant difference between the frequencies of respondents' gender and how it affected experience of ethical dilemmas the frequencies of both variables were subjected to Chi-square test. The results showed a Chi-square statistic of 0.395 with $\mathrm{p}$-value $=0.530$ (the level of significance for this study is 0.05 ). The observed difference was therefore not statistically significant.

\subsubsection{Age Versus Ethical Dilemma}

Most (36.6\%) of the respondents were in age group 35-39 yrs followed by 30-34 years at $27.7 \%$. Minimum and maximum ages of the respondents were 25 and 48 years respectively, giving a range of 23 years. The median and modal age was the same, 36 years. The distribution shows that a big percentage $(71.3 \%)$ of the nurses working in the critical care units is aged below 40. For age group variations, determination of any significant relationship between age and experience of dilemmas resulted to a Chi square statistic of 10.973 which has a $p$-value $=0.001$ confirming that the difference was highly significant.

\subsubsection{Professional Qualification Versus Ethical Dilemma}

More than two thirds of respondents $(67.5 \%)$ had a post basic diploma as the highest level of education, followed by diploma holders at $23.3 \%$. $7.5 \%$ had a basic degree in nursing while $1.7 \%$ who formed the least number had a master's degree. Further analysis of the results revealed that respondents with educational level of post basic diploma reported to have experienced more ethical dilemmas compared to those with basic diploma. To determine whether the above observation was significant results were subjected to Chi-square test which resulted to a Chi-square statistic of 6.455 (has p-value $=0.011$ ) which is highly significant.

\subsubsection{Work Experience Versus Ethical Dilemma}

Almost a half $(45.8 \%)$ of the respondents had work experience of less than 5 years in the critical care unit, followed by $30.8 \%$ who had experience of between $6-10$ years. This may be explained by the fact that majority of the nurses working in the critical care units are aged below 40 hence majority $(76.2 \%)$ have work experience ranging between 0 and 10 . Determination of influence of years of 
experience on experience of dilemmas showed that the observed difference was however not statistically significant i.e. a Chi-square statistic of 0.562 with a p-value of 0.454 was observed.

\subsubsection{Level of Knowledge of the Respondents Versus Ethical Dilemma}

The percentage of the respondents who were knowledgeable on ethical issues was $98.3 \%$. It was observed that respondents who had no knowledge at all reported to have experienced less ethical dilemmas compared to those with knowledge on ethical issues. To determine whether there was a significant relationship between the level of knowledge on ethical issues and experience of dilemmas the results were subjected to Chi-square test. The observed difference was highly statistically significant i.e. a Chisquare statistic of 16.791 with a $\mathrm{p}$-value $=0.001$.

\subsubsection{Ethics Content Taught Versus Dilemma}

$89.2 \%$ (107) of the nurses surveyed reported having ethics content integrated into regular nursing courses within their curricula. Out of these $12.5 \%, 9.2 \%, 65 \%$ and $2.5 \%$ reported to have had ethics content: integrated throughout the program of study, taught in a specific course, taught by nursing faculty and taught by non-nursing faculty respectively. $10.8 \%$ reported to have had no ethics content taught during their regular training.

$79.2 \%$ (95) of the nurses surveyed reported having ethics content taught in continuous professional development courses. Out of these $24.2 \%, 5 \%, 43.3 \%$ and $6.7 \%$ reported to have had ethics content: integrated throughout the program of study, taught in a specific course, taught by nursing faculty and taught by non-nursing faculty respectively. $20.8 \%$ reported to have had no ethics content in CPD programs.

\subsubsection{Availability of Workplace Resources}

Majority $(78.3 \%)$ of the respondents reported to have inadequate to totally inadequate resources to help them deal with ethics and human rights issues. Only $21.7 \%$ reported to have adequate resources (table 8 ). The respondents who said the resources were inadequate or totally inadequate reported to have experienced more ethical dilemmas compared to those who reported that to have adequate resources. However, this difference was not statistically significant i.e. the results showed a Chi-square statistic of 1.933 with a pvalue $=0.38$.

\section{Discussion, Conclusion and Recommendations}

\subsection{Discussion}

\subsubsection{Purpose of the Study}

This study has sought to ascertain what nurses experience as ethical dilemmas while working in the critical care areas and how they have dealt with these issues. Majority (80.8\%) of the respondents reported to have experienced ethical dilemmas while working in critical care setting. This finding was in line with the expectations of the researcher as previous studies conducted in other countries revealed that ethical dilemmas were an issue of concern to nurses and other health care professionals.

\subsubsection{Major Dilemmas Experienced}

The dilemmas of major concern to nurses included: those touching on end-of-life issues such as prolonging the dying process, withdrawing/ withholding treatment, resuscitation (DNR) orders (table 9). Others are those touching on patient care issues to include: unsafe nurse-patient ratios and allocation of scarce medical resource. Other issues are those touching on patient / human rights to include: rights of pediatric patients, and nursing of critically ill patients who may pose a risk to the nurses.

\subsubsection{Factors Affecting Nurses' Experience of Dilemmas}

The survey went ahead to assess the socio-demographic characteristics of the respondents which would affect the experience of ethical dilemmas. While there was no significant relationship noted between gender and experience of ethical dilemmas there was a significant relationship between age and experience of dilemma. The respondents aged below 35 years reported to have experienced less ethical dilemmas compared to those aged 35 years and above. This could be explained by the fact that majority $(65 \%)$ of the nurses working in the critical care units were aged 35 years and above group hence they (those aged below 35) formed a minority of those who experienced dilemmas.

There was no significant relationship observed between the length of working experienced and the experience of dilemma by the nurses. This could be explained by the fact that these dilemmas occur to all nurses regardless of their level of qualification as observed in previous researches conducted in other countries.

The study results revealed the level of professional qualification had a significant relationship with experience of ethical dilemmas. Respondents with post basic diploma reported to have experienced more ethical dilemmas compared to those with basic diploma. This may be explained by the fact that as the nurses become more knowledgeable in the area of critical care they are in a better position to identify a dilemma once encountered. What a person with a basic diploma may consider an ordinary situation may pose a dilemma to a more knowledgeable person with a better understanding of ethical issues.

When it came to assessing the amount and nature of ethics content integrated in both regular training and training and CPD, majority $(89.2 \%)$ of the nurses surveyed reported having ethics content integrated into regular nursing courses within their curricular. In addition, $79.2 \%$ reported having ethics content taught in continuous professional development courses. In both cases the content was taught by nursing faculty.

Although most (98.3\%) of respondents reported they were knowledgeable about ethics/human rights issues in nursing practice, $97.5 \%$ (97) of them believed they had a great/ very great need for more education on ethical issues. Only $2.5 \%$ 
(3) felt only a 'slight or no need' for such education.

It was observed that nurses who were not knowledgeable on ethical issues experience fewer dilemmas than those who were knowledgeable. The relationship between nurses' knowledge and experience of conflicts related to ethics and human rights issues in practice is particularly noteworthy. A research conducted earlier, showed that the ethics education of nurses (and their associated improved knowledge of ethical and human rights issues in practice) can paradoxically compound the frequency and intensity of ethical and human rights issues experienced by nurses in practice. This could occur due to their improved ability to identify ethical issues in places of work more readily than they did prior to their learning.

Looking at the work place resources available to support ethical decision making majority of the respondents cited inadequate work place resources. The respondents who said the resources were inadequate or totally inadequate reported to have experienced more ethical dilemmas compared to those who reported to have adequate resources. This may be explained probably by the fact that knowledge of availability of resources for instance ethics committees would enable one to utilize them in dealing with issues at work hence lessening their experience of dilemma.

\subsection{Conclusion}

Nurses in the Kenyatta national Hospital critical care units frequently experience ethical dilemmas in the course of their nursing practice that warrant focused attention by health service managers, educators and policy makers. The results of the study revealed that socio-demographic characteristics affected experience of ethical dilemmas by the respondents. These included: The nurses' level of professional qualification and the age.

Work place resources to support identification and resolution of ethical dilemmas were cited as inadequate. Nurses reported great need for ethics education.

\subsection{Recommendations}

As noted earlier, although $98.3 \%(118)$ of respondents (nurses) reported that they were knowledgeable about ethics/human rights issues in nursing practice, $97.5 \%$ (97) of them believed they had a great/ very great need for more education on ethical issues. Only $2.5 \%$ (3) felt only a 'slight or no need' for such education (table 4).

From the findings of this study I would recommend that the regulatory body reviews the ethics content included in the program of the nursing training syllabi to broaden it.

The employing institution (KNH) can help the nurses improve their knowledge on ethical issues through, formulation of ethical policies and standards, role modeling of ethical conduct by the managers and rewarding good moral conduct; through praise and recognition.

NB: The findings of this research can be used to facilitate a comparative study of the ethical issues experienced by other nurse working in other institutions for instance the private hospitals

\section{References}

[1] Oerleman A. JM (2015). Ethical problems in intensive care unit admission and discharge decisions: a qualitative study among physicians and nurses in the Netherlands. doi: 10.1186/s12910-015-0001-4. PMCID: PMC4344998.

[2] Whitlock EP et al. Behavioral Counseling Interventions: An Evidence-based Approach. Am J. Prev Med 2002; 22 (4): 26784. 2014.

[3] Sin Ho Jung (2014). Biom J. (2014). Stratified Fisher's Exact Test and its Sample Size Calculation. 10.1002/bimj.201300048.

[4] Oerlemans et al. (2015). BMC Med Ethics. 2015; 16: 9. Case Development on Nurses' Ethical Dilemmas with Physicians' and Nurses' Decision Making. doi: 10.1186/s12910-015-0001-4.

[5] Ethical decision making Net CE 2014. www.decisionlens.com.

[6] Gerald P. K. and Patricia K. (2015). Ethical Risks, Making Decisions, and Taking Action.

[7] Lin Jie (2015). International Journal of Nursing Sciences. The patient suicide attempt-An ethical dilemma case study. Volume 2, Issue 4, December 2015, Pages 408-413 http://dx.doi.org/10.1016/j.ijnss.2015.01.013.

[8] John Santilli J. and Vogenberg R. (2015). Am Health Drug Benefits. Key Strategic Trends that Impact Healthcare Decision-Making and Stakeholder Roles in the New Marketplace 2015 Feb; 8 (1): 15-20.

[9] Biddison LD et al. (2014). Ethical considerations: care of the critically ill and injured during pandemics and disasters: CHEST consensus statement. doi: 10.1378/chest.14-0742.

[10] Anderson A. (2014). Journal of caring sciences. Factors Affecting the Nurse-Patients' Family Communication in Intensive Care Unit of Kerman: a Qualitative study. doi: 10.5681/jcs.2014.008.

[11] Dong Won Park et al. (2015). Ethical Issues Recognized by Critical Care Nurses in the Intensive Care Units of a Tertiary Hospital. Journal of Korean Medical Science. Apr; 2014, 30 (4): 495-501. Published online 2015 Mar 19. doi 10.3346/jkms.2015. 30.4.495.

[12] Julie Bird (2016). Fierce healthcare. 10 emerging health care standards in 2016.

[13] Sue Stewart (2013). Should a Nursing Professional Report the Co-worker's Mistake?

[14] Kimberly C. (2015). Ethical Dilemmas in the Intensive Care Unit Treating Pain and Symptoms in Noncommunicative Patients at End of Life. Journal of Hospice and Palliative Nursing.

[15] Rose-Lima V et al. (2015). Conflicts between healthcare professionals and families of a multi-ethnic patient population during critical care: an ethnographic study. Crit Care. 2015; 19: 441. doi: 10.1186/s13054-015-1158-4.

[16] Nursing Council of Kenya (2012). Kenya national workforce and training analysis data, Nairobi, Kenya. 